\title{
Nuevos enfoques disciplinares en el patrimonio cultural. El peligro de la mercantilización patrimonial
}

\author{
María Mercedes Molina Liñán | Dpto. de Historia, Teoría y Composición Arquitectónica, Universidad de Sevilla \\ URL de la contribución <www.iaph.es/revistaph/index.php/revistaph/article/view/3871>
}

En la actualidad, el concepto tradicional de patrimonio histórico como herencia de nuestro pasado cultural queda superado por la convergencia de diferentes miradas y disciplinas, lo que ha supuesto la adopción de nuevos valores en los que entran en juego los modos de vida y la memoria, donde la hegemonía del valor histórico queda relegada a una horizontalidad compartida con otros, apareciendo en escena no sólo los valores tradicionales, sino adquiriendo conjuntamente protagonismo con los actuales, en los que la sociedad quiere ser partícipe de ellos, asumiéndolos como soporte identitario diverso y estando relacionados especialmente con su uso y gestión.

La diversidad de enfoques con la que puede tratarse el patrimonio y los continuos cambios tecnológicos, han dado lugar a la aparición de una importante variedad de disciplinas y profesionales implicados en la elaboración del discurso patrimonial, siendo el mismo un campo de estudio compartido desde cualquier perspectiva: "las fuentes disciplinares del patrimonio son tantas como tantos sean los lentes con los cuales se observe el objeto". Cada una de estas nuevas disciplinas plantea un "campo de conocimiento específico que se desarrolla a partir de su objeto de estudio a través de metodologías específicas" (IBARRA; BONOMO; RAMÍREZ, 2014).

De acuerdo con estas afirmaciones cada vez más se hace necesaria una actitud dialéctica entre los distintos profesionales dedicados al patrimonio, pues las aportaciones realizadas en el mismo objeto de estudio dan como resultado un conocimiento cuyo objetivo fundamental es el de salvaguardar el patrimonio, siendo en todo momento el bien el que marcará las pautas de trabajo a seguir, diseñando y demandando la actuación de intervención o preservación desde el mismo (CRIADOBOADO; BARREIRO, 2013).
Es por ello que, quedando superado el concepto de multidisciplinariedad en el que el bien patrimonial interesa a una única disciplina (aunque se nutre del conocimiento de otras afines), sólo desde la interdisciplinariedad o la transdisciplinariedad en su término más reciente, con una intención diferente que aspira al diálogo y la revisión permanentes, vemos el futuro del patrimonio, como la única manera de coordinarlo y trabajarlo; donde la transferencia de conocimiento de una disciplina a otra (AZKÁRATE, 2002) puedan plantear un horizonte de futuro que supere la mirada disciplinaria unidireccional y egocéntrica, de manera que confluyan y se aúnen diferentes bases del conocimiento en pro de garantizar el legado patrimonial del que somos depositarios.

La aparición de estas nuevas disciplinas de las que venimos hablando y, especialmente, las nuevas formas de gestión, han introducido factores que anteponen las dimensiones económicas y culturales, pasando "los bienes culturales a ser denominados recursos o destinos culturales" (MARTíNEZ, 2006).

No podemos olvidar que la propia palabra patrimonio hace gala en su origen etimológico de su carácter económico, pues recordemos que el término referencia el concepto de herencia y bien transmisible. De esta manera planteamos hacer una reflexión acerca de la actual tendencia mercantilista del mismo. En este sentido compartimos la opinión de Martínez Yáñez en su tesis doctoral ante la "tendencia exagerada del aprovechamiento productivo" de los bienes culturales, siendo los mismos más valorados en nuestros tiempos por su repercusión e incidencia económicas que por los valores que les son inherentes.

En definitiva, con la aparición de nuevos valores, profesionales y tecnologías implicados en cuestiones patrimo- 


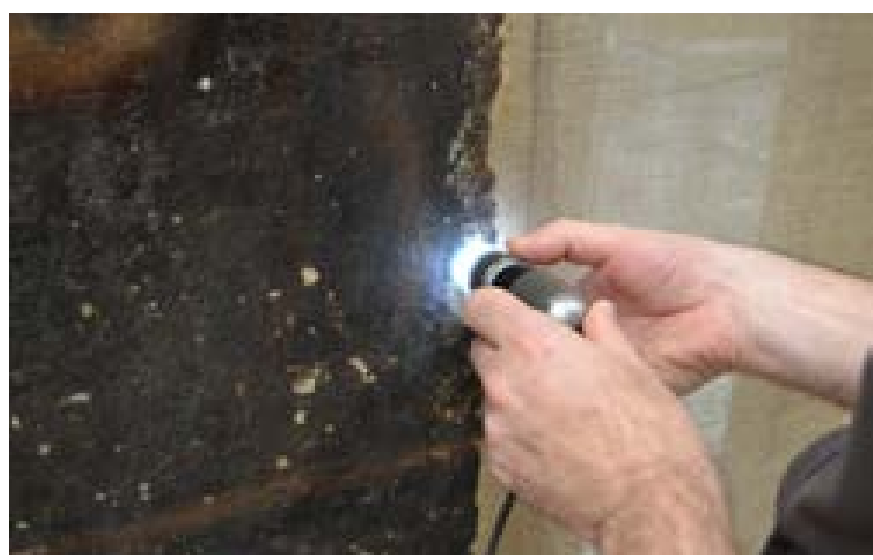

Aplicación de microscopio electrónico a obra al óleo sobre lienzo

niales, se debería garantizar una adecuada transmisión no sólo testimonial del bien, sino de la imagen proyectual del mismo a la ciudadanía. Sin embargo, en numerosas ocasiones y ante la imposibilidad de su gestión económica por parte de los distintos organismos públicos, existe un importante peligro de mercantilización y banalización del legado patrimonial, desvirtuando los valores de los que son portadores.

\section{BIBLIOGRAFÍA}

- AZKÁRATE, A. (2002) La interdisciplinariedad, ¿una concesión al lenguaje políticamente correcto? En II Bienal de Restauración (Vitoria-Gasteiz, 21-24 de noviembre de 2002). Vitoria-Gasteiz: Fundación Catedral Santa María, 2004, pp. 41-45

- CASTRO-MARTínEZ, E.; FERNÁNDEZ-BACA, R. (2012) La innovación en el patrimonio cultural: un espacio de confluencia de diversas bases de conocimiento. Working Paper Series, n. ${ }^{\circ}$ 2012/07, 2012, pp. 1-26

- CRIADO-BOADO, F.; BARREIRO, D. (2013) El patrimonio era otra cosa. Estudios atacameños, n. ${ }^{\circ} 45,2013$, pp. 1-15 $<$ http://www.estudios-atacamenos.ucn.cl/revista/numero45. html> [Consulta:25/01/2017]

- IBARRA, M.; BONOMO, U.; RAMíREZ, C. (2014) El patrimonio como objeto de estudio interdisciplinario. Polis. Revista Latinoamericana, n. ${ }^{\circ} 39,2014$, pp. 1-9 <https://polis. revues.org/10540> [Consulta:25/01/2017]

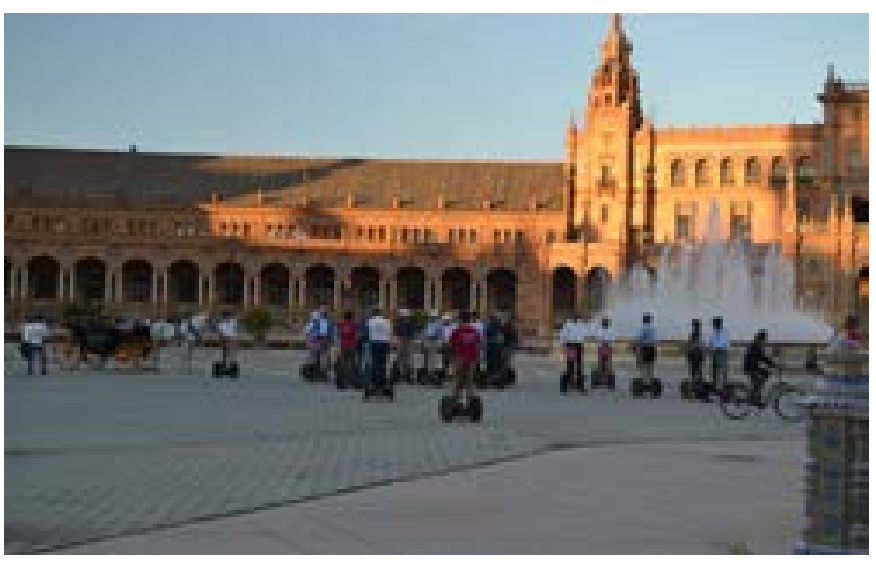

Segway en plaza de España. Parque de María Luisa, Sevilla | fotos M. ${ }^{a}$ Mercedes Molina Liñán

- JORGE, C.; LUQUE, I. (2005) Las profesiones del patrimonio cultural. $\mathrm{PH}$ Boletín del Instituto Andaluz del Patrimonio Histórico, n. ${ }^{\circ}$ 54, 2005, pp. 57-59 <http://www. iaph.es/revistaph/index.php/revistaph/article/view/2004\#. WJBr50dBGFY> [Consulta:25/01/2017]

- MARTÍNEZ YÁÑEZ, C. (2006) El patrimonio cultural: los nuevos valores, tipos, finalidades y formas de organización. Tesis doctoral. Dpto. de Historia del Arte, Universidad de Granada, 2006

- NÚÑEZ, C. (2014) El trabajo multidisciplinar en el patrimonio. En MUÑOZ, C. (dir.); RAMOS, M. (ed.) Ciencias Tecnológicas y Agrarias: Arquitectura T-I Handbooks. Bolivia: USFX, 2014, pp. 19-34

- RAMOS, D. (2016) Sobre el concepto de "patrimonio cultural". Mito Revista cultural, n. ${ }^{\circ}$ 39, 2016 <http://revistamito. com/concepto-patrimonio-cultural/> [Consulta:25/01/2017] 